Article

\title{
A Sustainable Approach for the Management and Valorization of Underwater Cultural Heritage: New Perspectives from the TECTONIC Project
}

\author{
Michela Ricca ${ }^{1, *(D)}$, George Alexandrakis ${ }^{2}($ $)$, Alessandra Bonazza ${ }^{3}\left(\right.$ ) , Fabio Bruno ${ }^{4}(\mathbb{D}$, \\ Barbara Davidde Petriaggi ${ }^{5}$, Dolores Elkin ${ }^{6}$, Antonio Lagudi ${ }^{7}$, Stephane Nicolas ${ }^{8}$, \\ Michal Novák ${ }^{9}$, George Papatheodorou ${ }^{10}$, Javier Prieto ${ }^{11} \mathbb{D}$, Marco Ricci ${ }^{12} \mathbb{D}$, \\ Antonio Vasilijevic ${ }^{13}$ and Mauro Francesco La Russa ${ }^{1,2}$ \\ 1 Department of Biology, Ecology and Earth Sciences (DiBEST), University of Calabria, \\ 87036 CS Arcavacata di Rende, Italy; mlarussa@unical.it \\ 2 Institute of Applied \& Computational Mathematics, Foundation for Research \& Technology-Hellas, \\ 70013 Heraklion, Greece; alexandrakis@iacm.forth.gr \\ 3 Institute of Atmospheric Sciences and Climate, National Research Council (ISAC-CNR), Via Gobetti 101, \\ 40129 Bologna, Italy; a.bonazza@isac.cnr.it \\ 4 Department of Mechanical, Energy, and Management Engineering (DIMEG), University of Calabria, \\ 87036 CS Arcavacata di Rende, Italy; fabio.bruno@unical.it \\ 5 Istituto Centrale per il Restauro, Via di San Michele, 00153 Rome, Italy; barbara.davidde@beniculturali.it \\ 6 Consejo Nacional de Investigaciones Científicas y Técnicas (CONICET), \\ and Instituto Nacional de Antropología y Pensamiento Latinoamericano, 3 de Febrero, \\ Buenos Aires 1378-1426, Argentina; lolielkin@hotmail.com \\ 7 3D Research s.r.l., Ponte P. Bucci, 45/C, 87036 CS Arcavacata di Rende, Italy; antonio.lagudi@unical.it \\ 8 PROLEXIA, Centre d'Activité des Playes ZE Jean Monnet, 865 Avenue de Bruxelles, 83500 La Seyne Sur Mer, \\ France; snicolas@prolexia.fr \\ 9 SYNPO, Akciová Společnost, S. K. Neumanna 1316, 53207 Pardubice, Czech Republic; \\ michal.novak@synpo.cz \\ 10 Department of Geology, Laboratory of Marine Geology and Physical Oceanography, University of Patras, \\ 26504 Patras, Greece; gpapathe@upatras.gr \\ 11 BISITE Research Group, University of Salamanca, C/Espejo s/n, 37007 Salamanca, Spain; javierp@usal.es \\ 12 Department of Informatics, Modeling, Electronics and System Engineering (DIMES), University of Calabria, \\ 87036 CS Arcavacata di Rende, Italy; marco.ricci@unical.it \\ $13 \quad \mathrm{H}_{2} \mathrm{O}$ Robotics, Unska, 31000 Zagreb, Croatia; Antonio.Vasilijevic@fer.hr \\ * Correspondence: michela.ricca@unical.it
}

Received: 2 May 2020; Accepted: 16 June 2020; Published: 18 June 2020

check for updates

\begin{abstract}
Documentation and conservation of underwater cultural heritage (UCH) are crucial to preserving humankind's history and traditions, safeguarding tangible testimonies of past human life while ensuring its accessibility to future generations. The TECTONIC (Technological Consortium TO develop sustainability of underwater Cultural Heritage) project is promoting an intersectoral collaboration between academic and non-academic professionals (i.e., archaeologists, conservators, geologists, engineers, etc.) working on different topics related to UCHs, to find solutions to the issues still existing in the field. The overall aim is the exchange of skills for the improvement and assessment of innovative materials and techniques to develop solutions and marketable products for the conservation and management of the $\mathrm{UCH}$, sustainably. To achieve its overall aim, TECTONIC is undertaking activities driven by the following objectives: (a) the study, documentation, and mapping of selected $\mathrm{UCHs}$; (b) the creation of decision-support tools for UCH risk assessment in a changing environment; (c) the initiation of conservation studies and protocols for conservation activities; (d) the development of open and low-cost robotic solutions for the inspection of $\mathrm{UCH}$; and (e) the raising of public awareness and knowledge about UCH. All the objectives are devoted to stimulating new sustainable
\end{abstract}


ideas that would bring the growth of cultural tourism and the development of new marketable products by capitalizing on the research results.

Keywords: archaeology; protection; materials; sustainability; tourism; underwater cultural heritage $(\mathrm{UCH}) ; 3 \mathrm{D}$

\section{Introduction}

Underwater cultural heritage (UCH), although today still little valued, represents a key and crucial factor to preserve humanity's traditions, customs, and history, safeguarding tangible testimonies of past life while assuring its sustainable accessibility to future generations. Bearing in mind the socio-economic-tourism aspect, UCHs must be considered a source of knowledge that create a positive impact on the cultural tourism chains and flows. UCH can, therefore, be closely related to sustainable tourism activities thanks to the presence on the seabed of artifacts, ruins, remains, wrecks, etc., of historical or archaeological interest. Europe and the rest of the world are rich in UCH, due, for example, to sinking of ancient ships, sea-level rise, or geological phenomena causing gradual uplifts or descents of the earth's surface; however, just a few countries are skilled at exploiting them as a further source of knowledge and as major tourist attractors, ensuring their financial sustainability through proper management models.

In recent decades, Europe first, and then many of the scientific and international cultural heritage $(\mathrm{CH})$ protection organizations, agreed on promotion, protection, and, where possible, in situ preservation of underwater archaeological and historical heritage in order to fully enjoy these precious assets lying under the sea surface (i.e., The Valetta treaty [1] and UNESCO's Convention for the Protection of the UCH [2]. Specifically, the UNESCO Convention [2] provided a detailed states-cooperation system (up until now, the convention has been ratified by 63 countries). They set out the basic guidelines for the protection of $\mathrm{UCH}$; one of the main principles of that convention states that the in situ preservation of $\mathrm{UCH}$ should be considered as the first option before engaging in any further activities, such as those intended for the creation of tourist trails and itineraries or research surveys.

In terms of the management perspectives, nowadays the preservation and conservation of underwater cultural sites and objects require the adoption of sustainable and affordable solutions aiming primarily at preserving them as well as increasing the knowledge about them [3-10]. This creates several research challenges that are intrinsically interdisciplinary because they involve the strict collaboration among various experts from different sectors like archaeology, geology, biology, oceanography, engineering, robotics, computer science, and a lot of other disciplines. Starting from these primary challenges, it will then be possible to make coastal areas tourism-based economies with the potential to include underwater cultural and sustainable activities.

From the beginning of underwater archaeology and related disciplines, scientists and experts working on such specific and innovative subjects have been facing common and considerable challenges, especially in the aftermath of the global economic crisis [11-20]. Those challenges can be identified as the (a) lack of coordinated regulatory and planning policies, methods, tools, and resources tailored to support a sustainable economic development that includes $\mathrm{UCH}$; (b) ineffective protection of $\mathrm{UCH}$ - particularly in developing countries-and inability to use them as assets for sustainable and responsible tourism development; (c) insufficient measures to tackle the effects of climate changes or the damage they suffered in the underwater environment; and (d) lack of knowledge and, most of all, of techniques and materials suitable for underwater in situ conservation and protection (e.g., tools for monitoring and mapping the decay phenomena, or for cleaning and/or treating the archaeological/historical remains).

Moving from these considerations, the present work wants to explain the main objectives of the TECTONIC project (Technological Consortium TO develop sustainability of underwater 
Cultural Heritage) by promoting an intersectoral collaboration between academic and non-academic professionals, such as technical experts, archaeologists, conservators, geologists, engineers, and computer scientists, working in different topics that are related to the $\mathrm{UCH}$, in order to respond to the above-mentioned challenges and find solutions to the complex issues still existing in the field. TECTONIC's overall aim is the exchange of skills and expertise for the implementation, improvement, and assessment of innovative materials, techniques, tools, and methodologies in order to develop solutions and marketable products for the conservation, restoration and sustainable management of the UCH (objects, artifacts, structures, remains, etc.). The exchanges will be supported by specific training programs and in-lab and on-the-field activities, aimed at knowledge and idea development, and then dissemination of the main results to the general public and stakeholders. More specifically, this work, in the frame of TECTONIC, intends to focus on the study of different types of historical/archaeological materials (i.e., stones, metals, etc.) lying underwater at three different pilot sites located in Italy, Greece, and Argentina) [20-23]. The choice of the sites, two of which in the Mediterranean basin and one in the Atlantic Sea, was made in order to experiment with new methods and technologies suitable for the conservation of UCHs in several environmental conditions and on different materials, also making comparisons possible, based on the results that will be achieved. Special attention will be devoted to the in-depth research related to the study of decay phenomena and the analysis and development of the most suitable methods for the conservation and (when applicable) restoration of the underwater remains, considering all the environmental parameters that may be involved (i.e., T, $\mathrm{pH}$, depth, water salinity, wave motion, currents, burial conditions, biological growth, physical and chemical agents, etc.).

In order to address this challenge, TECTONIC is bringing together internationally leading research organizations and companies from seven different countries working in the UCH field. The combined effort of different experts and competences will help in filling the knowledge, methodological and technical gaps in the underwater archaeology and it will be of utmost importance for the implementation of the specific objectives of the project.

To promote the exchange of skills, the following research goals will be achieved: (a) improve existing materials and experiment with new ones suitable for the protection of remains and for limiting the decay processes underwater (e.g., due to biological growth, corrosion, etc.); (b) develop more effective forecasting models capable of quantifying degradation phenomena occurring in UCH by exploiting artificial intelligence (AI) methods applied to environmental parameters data and multi-sensors images acquired periodically on underwater pilot sites; (c) extend the use of virtual and augmented reality technologies for developing applications in which the public can enjoy the reconstructions of the underwater sites by experiencing a virtual dive in the past (for non-divers) [24].

One of the main objectives of the present work is to contribute to the program of the "2030 United Nations Agenda for Sustainable Development and the Related 17 Sustainable Development Goals (SDGs), with particular regard to the Objective 11.4, aimed at "strengthening commitments to protect and safeguard the world's cultural and natural heritage". The achieved sustainability measures will be useful as result indicators and policies, encouraging the best sustainability and management practices in tourism development and environmental and social impact. Moreover, sustainability measures related to $\mathrm{UCH}$ will provide a useful guide to experts in the field, operators, stakeholders, etc. in order to preserve and protect underwater cultural resources in situ and, as a result, to assist the EU strategies (as well as those in other parts of the world) in minimizing the impact to the marine ecosystem and adapting to climate changes.

This project has received funding from the European Union's Horizon 2020 Research and Innovation (RISE) program under the Marie Skłodowska-Curie actions. The RISE program encourages cross-border and cross-sector collaboration through sharing knowledge and ideas from research to market and vice versa within Europe and beyond, with the participation of partners from six EU countries (Italy, Greece, Croatia, Czech Republic, Spain, and France) and an Extra-EU one (Argentina). 


\section{Methodological Approach and Objectives}

Starting from the in-depth knowledge of the pilot sites, the methodological approach (Figure 1) planned within the project will lead to the improvement of the already existing management practices for $\mathrm{UCH}$ sites, giving as main results innovative tools and materials for promoting conservation strategies of underwater sites [25-27], as well as their knowledge, promotion, and fruition in a sustainable way. This approach will be driven by several steps which can be summarized as follows: (a) the realization of a network of knowledge and exchanges of skills through training activities; (b) the analysis and study of the three pilot sites (from historical/archaeological, environmental, geological, biological, etc. point of view) along with the recording of data useful for 3D reconstruction and mapping; (c) the implementation of monitoring systems for the underwater environment through the realization of a platform by using artificial intelligence (AI); (d) the testing of antifouling/protective materials/coatings suitable to limit decay phenomena (according to the type of selected objects within the pilot sites); and (e) the implementation of robotic solutions for the inspection, documentation, and monitoring of $\mathrm{UCH}$.

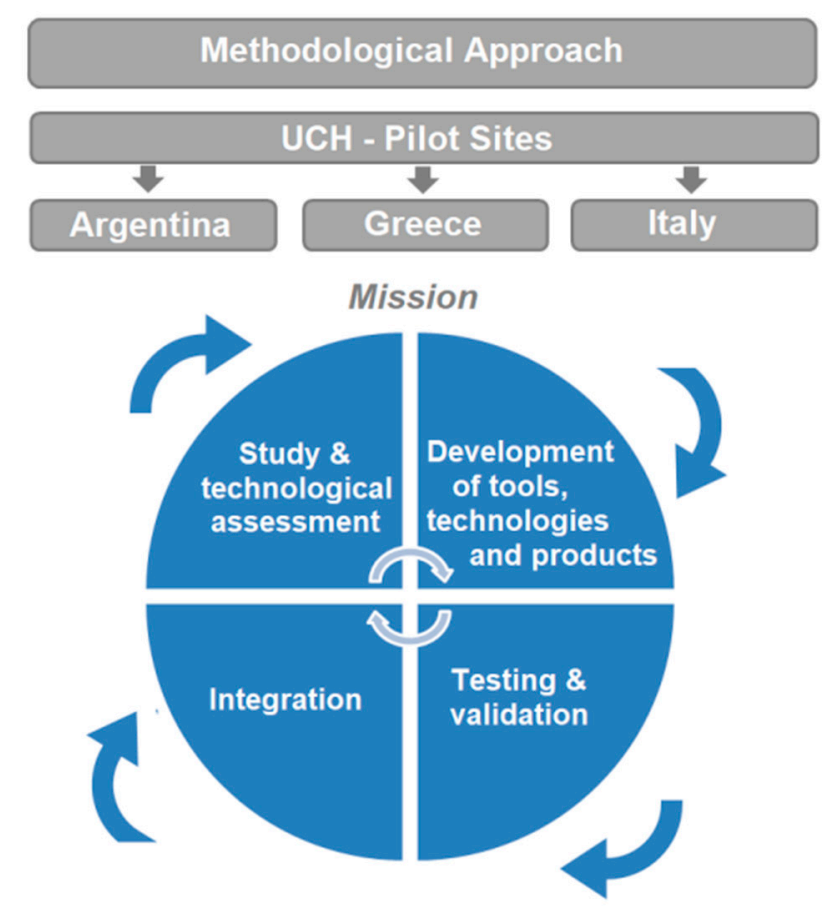

Outcomes :

To improve management strategies in $\mathrm{UCH}$

To improve awareness, knowledge \& Know-how

Development of underwater cultural tourism (economy)

Improvement of conservation protocols and strategies

Assessment of new marketable tools and materials for UCH

Figure 1. Plan of TECTONIC project. UCH-underwater cultural heritage.

Finally, the outcomes achieved from the above steps will be integrated and applied to the three case studies to develop new strategies for managing $\mathrm{UCH}$, as well as new tourist and marketable products. At the same time, dissemination and promotion activities related to the project results, addressed to 
the general public and not only to experts in the sector and stakeholders, will be carried out by the use of virtual and augmented reality technologies to enjoy virtual dives in the past [21,24,28-33].

Following the methodological approach, TECTONIC will undertake innovation and development activities driven by the six following objectives.

The first objective is addressed to the study, documentation, and 3D reconstruction of the selected pilot sites located underwater. An in-depth study of the historical/archaeological sites and the creation of detailed maps will be conducted, offering a large-scale overview of the ancient submerged areas, showing details about positions, materials, historical, and environmental info, routes, and trails for tourists, etc. Particular attention will be devoted to the three pilot sites, selected based on the historical importance and state of preservation, considering both the Mediterranean basin and the Atlantic Ocean, making possible comparisons between the different marine environments and conditions. Investigation actions on materials will focus on stone and metals which are the heritage materials prevailing at the three sites. The latter ones will be first evaluated from a historical and archaeological point of view; then environmental, physical, chemical, and biological conditions will also be taken into consideration, sharing and comparing data and protocols used for data collection. Additionally, there will be an exchange of best practices and regulations related to the study of UCH in Europe and worldwide, with the final aim to share a common methodology. Data will be used in order to create underwater historical/archaeological maps to be used as additional tools for UCH management and will be drawn up and improved also on the basis of existing studies and recent fieldwork, covering all the latest data and research. The creation of such a detailed map will increase the knowledge of selected submerged sites and will also have a strong socio-economic and tourism impact. Finally, thanks to the development of innovative opto-acoustic multi-resolution techniques focused on 3D reconstruction of underwater archaeological sites, additional data for site mapping will be made available, providing in this way a cost- and time-effective, accurate, and fully-detailed means of surveying [28-35].

The second objective concerns the development of a decision-support tool for UCH risk assessment in changing environments. Monitoring of historical/archaeological sites is necessary in order to know their state of conservation and assess causes of deterioration processes in terms of driving environmental/pollution parameters. Nowadays, the use of sensors and probes is one of the most cost-effective methods for monitoring environmental changes as well as for assessing the state of preservation of archaeological items and sites in underwater environments [32]. Within this objective, a decision-support tool for risk assessment of $\mathrm{UCH}$ that will integrate environmental monitoring by the application of existing tools and models will be developed. A platform to integrate data monitored by different commercial probes and sensors will develop, also by using other open data sources. This platform will be able to support heritage managers in the definition of appropriate monitoring approaches and solutions for the sustainable preservation of underwater archaeological remains. Further, the acquired data will be elaborated in order to propose possible models of deterioration of stones and metals in underwater conditions due to major environmental changes (e.g., temperature, $\mathrm{pH}$, water salinity). The platform developed will collect all these data in order to build a knowledge base with information about the decay evolution of the samples and the environmental conditions. This data will be processed by the means of AI techniques to infer subjacent relations among the parameters registered and to perform a comparative data analysis able to define which environmental aspects have a deeper impact on the preservation of the underwater heritage. With this information, the decay process can be modeled, and an accurate preservation protocol can be incorporated into the platform, as an intelligent tool (decision-support system) [36].

The third objective is related to conservation studies, protocols, and suitable procedures for preservation/conservation activities. Before making $\mathrm{UCH}$ areas available to the public and tourism, the issue of the correct safeguarding, preventive conservation, and periodic maintenance of the submerged items must be addressed (e.g., cleaning, restoration, protective treatments, maintenance, etc.). Being underwater, ancient sites are subjected to a particularly aggressive environment, so the $\mathrm{UCH}$ state of conservation must be firstly assessed by considering also the exposure 
and/or burial conditions. The "minimum intervention policy" principle will guide the activities implemented to accomplish this objective, in order to address only the critical factors affecting the conservation of the archaeological remains over time. Invasive sampling and investigations will be therefore avoided. For example, in the cases where removing biofouling growth is considered necessary, non-polluting and eco-friendly products will be used (e.g., innovative nanostructured materials). After a preliminary study of decay phenomena that affect materials in sea-water with a probable sampling of material and analytical investigations in the laboratory, then the tested suitable protective products will be applied to the different types of archaeological materials to prevent decay processes.

The fourth objective will be devoted to the development of open and low-cost robotic solutions for the inspection, documentation, and monitoring of UCH. Underwater archaeological sites are generally difficult to access, and more hazardous, compared with working on dry land. In the last years, a variety of different systems have been used for surveys and research efforts including remotely operated vehicles (ROVs), autonomous surface vehicles (ASVs), and autonomous underwater vehicles (AUVs), each of them equipped with different types of tools and sensors (robotic arms, sonars, optical cameras, etc.). These kinds of vehicles help scientists to survey the sites at major depths and to cover bigger areas of exploration due to the greater autonomy and fewer difficulties compared to direct human-led exploration. Specifically, regarding archaeological applications, great efforts have been focused on the documentation, preservation, and conservation of our cultural heritage, which is an important part of underwater archaeologists' work. Based on previous research and existing systems, this objective aims to design, develop, and validate innovative, marketable, and competitive robotic solutions, based on open and low-cost technologies, for the inspection, documentation, and monitoring of UCH. In particular, a commercial off-the-shelf (COTS) recreational ROV/AUV platform, based on an open configurable architecture, will be developed. This will be done by integrating a suite of sensors onboard that are capable of collecting environmental data, to automatically acquire data coming from remote sensors placed on the seabed, or to carry out bathymetric surveys. The customized ROV will be tested at the pilot sites in order to ensure that it meets the requirements of underwater operators working in the UCH.

The last two objectives, respectively 5 and 6, concern the transfer of skills and knowledge and the raising of public awareness and knowledge about the importance to preserve the underwater historical and archaeological heritage. In this frame, training events, seminars, and conferences will be organized and data collected will be presented to the public in an engaging way, so that people can easily understand the need to preserve $\mathrm{UCH}$ for the future generations. Current systems for underwater 3D scanning (photogrammetry) will be optimized for achieving both higher speed and improved visual precision to be able to scan UCH sites. These 3D scans will then be imported into a virtual reality environment using the Unity3D engine to create a virtual museum viewable on several different platforms, i.e., Oculus Rift, Windows MR, HTC VIVE, Google Daydream, and smartphone cardboard VR (Virtual Reality). In combination with the virtual reality environment, videos collected by the ROV (see objective 4) will enable the users to join the ROV pilot in a first-person perspective to relive the dive and entry into the cultural heritage site. Additionally, thanks to the use of 3D reconstructions and virtual/augmented Reality [28-35], the underwater archaeological assets will become remotely accessible without any constraint of time and space even by people that are not familiar with scuba diving or other forms of accessing $\mathrm{UCH}$ and, most important, by people with reduced mobility.

\section{Pilot Sites}

The project has been planned to be developed and structured in several phases, ranging from study and technological assessment; development of tools, technologies and products; and integration, testing and validation activities. All the methodologies and tools will be tested in the three scenarios described hereafter, chosen as pilot sites of all activities and investigations of the project (Figures 2-5). 


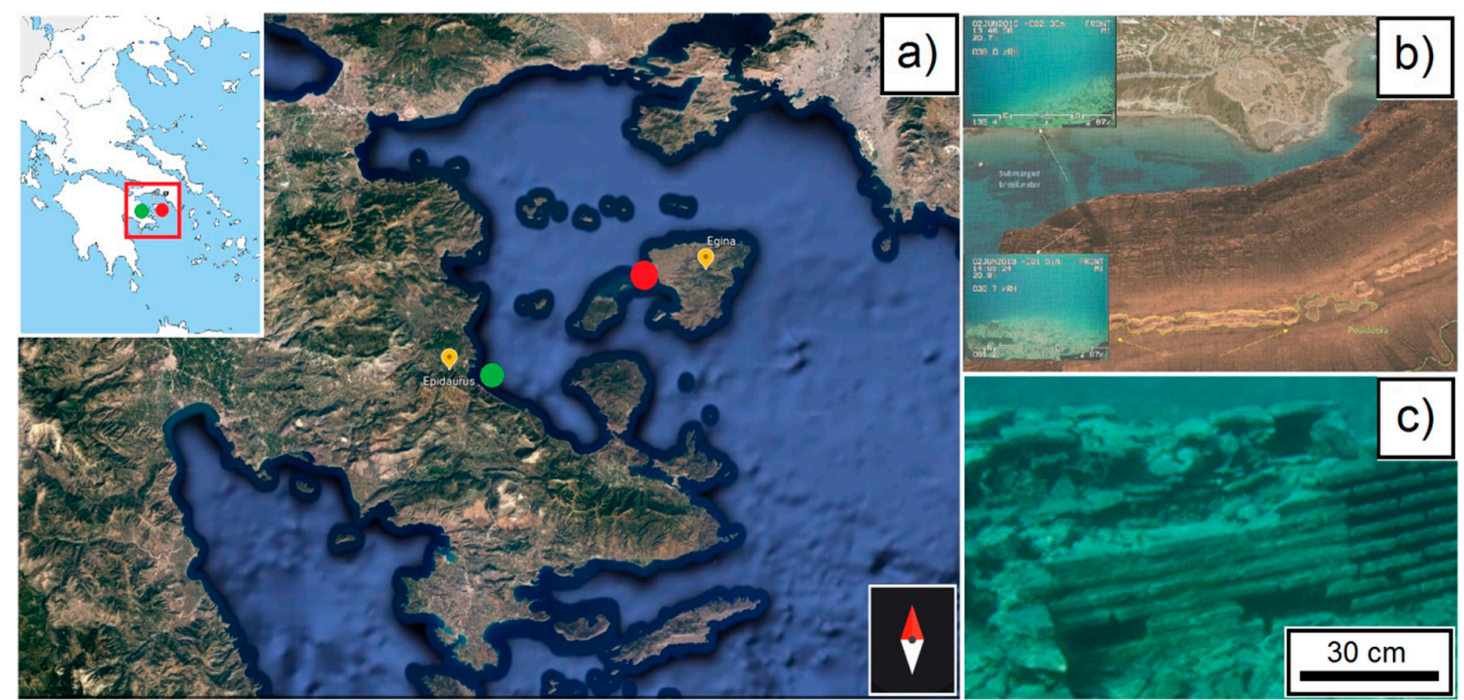

Figure 2. Aerial view by Google Earth of the Aegina Island located in Argosaronic Gulf (Aegean Sea), and Epidaurus, in the Peloponnese region (Greece) (a); side scan sonar sonograph and representative underwater pictures of the ancient Aegina harbor (b) and ruins of the Roman Villa of Dolia at Epidaurus (c). Photo credits: University of Patras (b); www.icr.beniculturali.it (c). Note: In (a), the red and green dots localize, respectively, the Aegina harbor and the underwater site at Epidaurus.

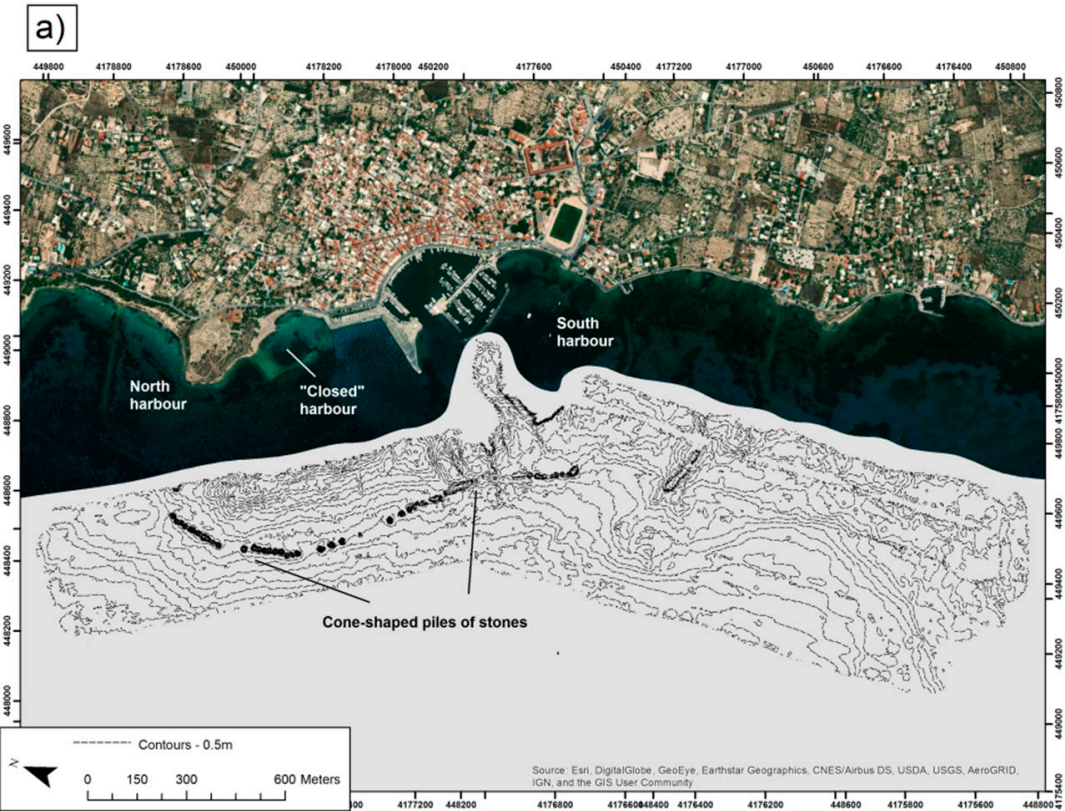

b)
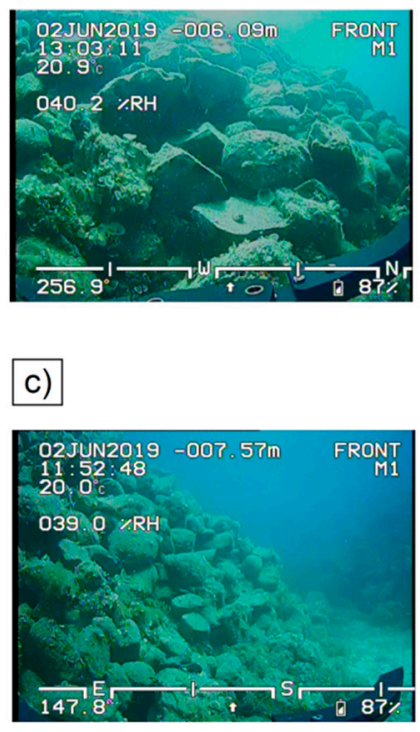

Figure 3. Detail bathymetric map of the ancient harbor of Aegina based on multibeam data (a) and underwater photos showing the cone-shaped piles constructed by stones, part of the submerged ancient harbor installations $(\mathbf{b}, \mathbf{c})$. Photo credits: University of Patras. 


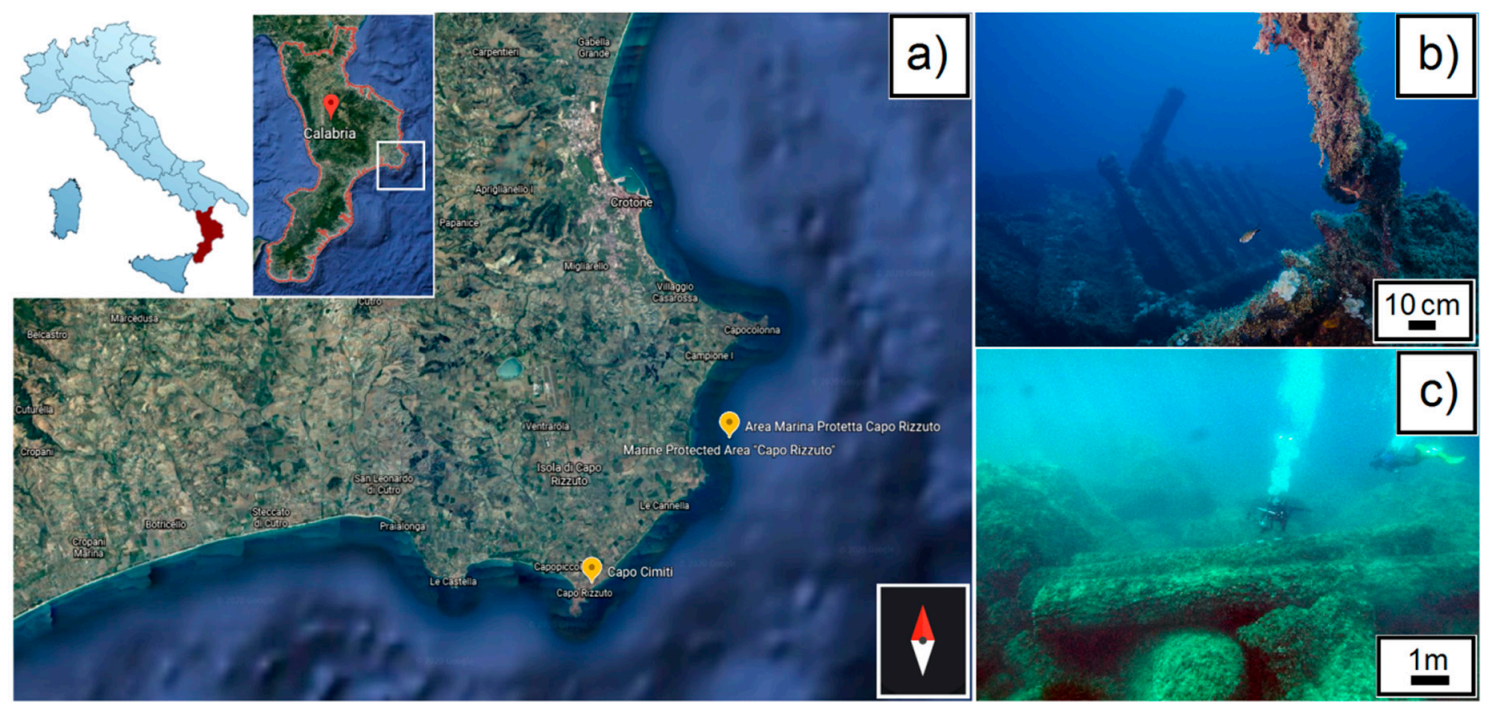

Figure 4. Aerial view by Google Earth of the Marine Protected Area "Capo Rizzuto" located in southern Italy, in the Calabria region (a) and underwater pictures of the Bengala (b) and Capo Cimiti (c) shipwrecks chosen as Italian pilot sites. Photo credits: Collina M. (b); Capulli M. in reference [23] (c).
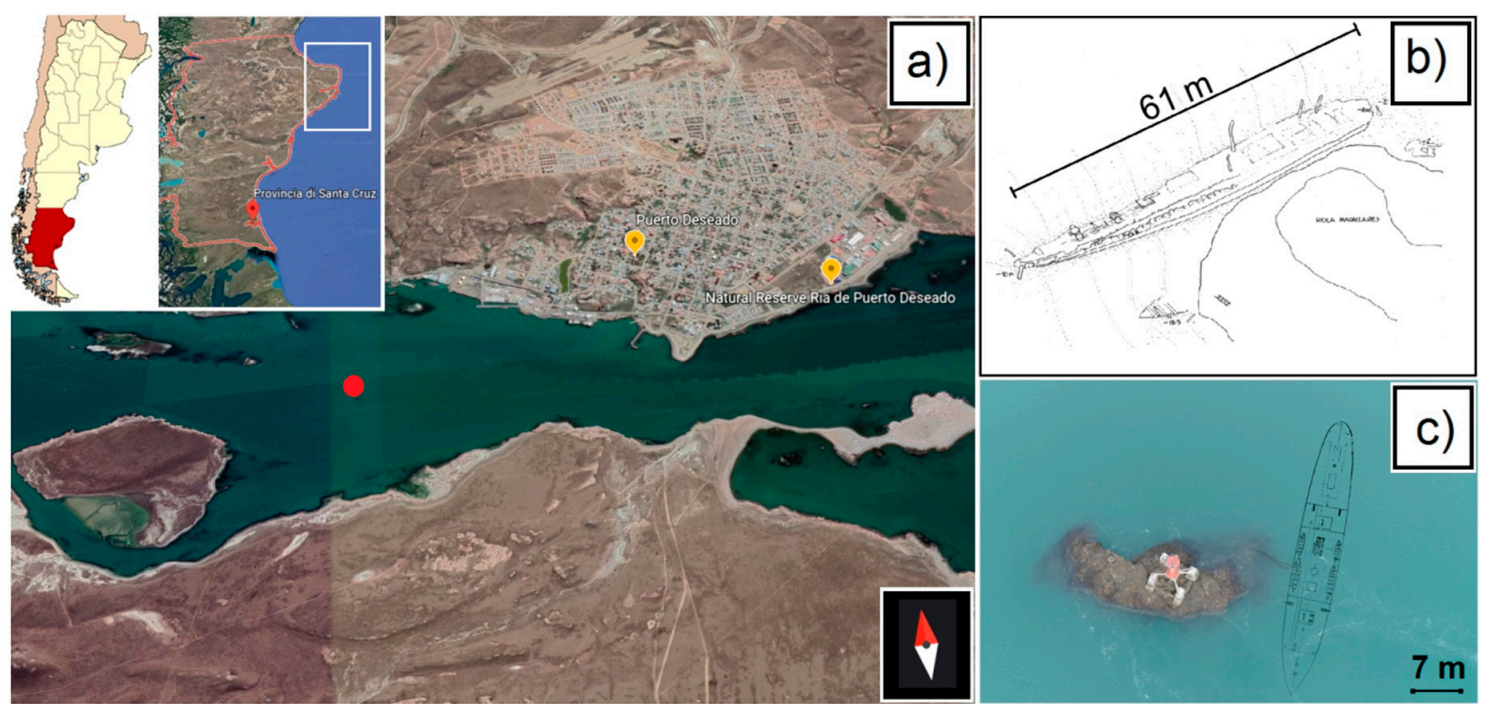

Figure 5. Aerial view by Google Earth of Puerto Deseado, located in southern Argentina, in the Santa Cruz province (a); underwater sketch of the historic steamer Magallanes (b); and location of the shipwreck in the marine area (c). North and south points of the site: $47^{\circ} 45^{\prime} 31.27^{\prime \prime}-65^{\circ} 55^{\prime} 24.96^{\prime \prime}$ and $47^{\circ} 45^{\prime} 33.04^{\prime \prime}-65^{\circ} 55^{\prime} 26.28^{\prime \prime}$, respectively. Drawing: Cristian Murray (b,c). Note: In (a), the red dot localizes the historic steamer Magallanes in the natural reserve Ría de Puerto Deseado.

\subsection{Saronic Gulf, the Ancient Aegina Harbor and Epidaurus-Greece}

The selected Greek pilot sites are located in the Saronic Gulf, an area very interesting for the geological and archaeological point of view, an ideal natural laboratory to perform the TECTONIC project objectives (Figures 2 and 3). At least seven submerged very important harbors and port installations of classical and Roman antiquity have been found along the Saronic coast (Kenchreai, Epidaurus, Salamis, Zea, Mounichia, Sounion, and Aegina). Among these, in the frame of TECTONIC, the following pilot sites were selected.

1. "The ancient Aegina harbor" (Figure 2a,b and Figure 3) installations are one of the largest artificial harbors of classical antiquity, with a total length of $1600 \mathrm{~m}$ and an average width of $270 \mathrm{~m}$, 
occupying an area of 500,000 $\mathrm{m}^{2}$. Installations include the north harbor, the "closed harbor" in the north part of the south coast, the commercial harbor to the south, and a wide anchorage area between them (Figure 3a). The most impressive part of the submerged ancient harbor is the linear arrangement of cone-shaped piles running parallel to the present-day coastline (Figure 3b,c); The submerged harbor installations are located about $3 \mathrm{~m}$ below the present sea level. This subsidence is compatible with the findings in the Sounio archaeological site $(2.5-3.0 \mathrm{~m})$ [19] and in the Salamis Straits $(2.5 \mathrm{~m})$, where the Salamis naval battle took place [20]. The ancient harbor of Aegina, due to its complexity, constitutes an ideal environment for applying state-of-the-art methods and techniques for mapping and 3D reconstructing archaeological sites.

2. "The Ancient Epidaurus" (Figure 2a,c) is one of the most important archaeological sites of the country. It is famous for the ancient theatre with amazing acoustics. However, this is also known for the recent excavation and restoration activities conducted in the submerged "Villa of the Dolia" (Figure 2c) off the coast of the ancient city. The archaeological surveys carried out until today along the coast of the Agios Vlassis Bay in the Nissi peninsula, which hosts the acropolis of Ancient Epidaurus, discovered the remains of a monumental building belonging to the classical or Hellenistic age, with clear signs of Roman age reuse. The underwater archaeological remains of Ancient Epidaurus also include the ancient harbor [21].

\subsection{Marine Protected Area Capo Rizzuto, the Shipwrecks of Capo Cimiti and Bengala_Italy}

The pilot sites selected in Southern Italy are located within the Marine Protected Area "Capo Rizzuto" (Crotone) (Figure 4a), instituted in 1991 and located in the Ionian Sea. It extends for 15,000 hectares and represents the largest marine reserve of Italy. The submerged area and the coasts are rich with historical traces such as Roman and Greek ruins, ancient fortresses, shipwrecks, and artifacts constituted by stone and other materials that will be subjects of the project. The attractions selected within the project consist of the submerged shipwrecks of the "Bengala" (Figure 4b) and "Capo Cimiti" (Figure 4c). The Bengala shipwreck is located 0.9 miles from Isola di Capo Rizzuto (Italy) at a depth of $28 \mathrm{~m}$. The vessel, which was built in 1873 in the English yards Osborne, Graham \& Co, originally had a raw displacement of 1.454 metric tons and a length of $75 \mathrm{~m}$. Currently, the wreck is broken into two parts that lie on a sandy bottom strewn with rocks, at a depth of almost $30 \mathrm{~m}$. It is possible to view the imposing stern with the four-blade propeller, in the middle of the boiler system with the external combustion engine next to it where you can admire the connecting rods, crankshaft, and the propeller shaft tunnel. The Capo Cimiti wreck is located north of the namesake locality, about $70 \mathrm{~m}$ from the cliff and at 6-7 m depth. It was a navis lapidaria carrying five smooth columns made in stone material and up to $9 \mathrm{~m}$ long $[22,23]$.

\subsection{Historic Steamer Magallanes, Puerto Deseado—Santa Cruz Province, Argentina}

The shipwreck site of the historic steamer Magallanes (Figure 5), built in Scotland in 1880 and wrecked in the Southwestern Atlantic Ocean in 1887, represents the pilot site for Argentina. It had a steel hull, mixed propulsion (steam and sails); its size was $61 \mathrm{~m}$ in length, $6.7 \mathrm{~m}$ width, and a depth of $4 \mathrm{~m}$. The remains are located in the Ría Deseado (Deseado estuary), Santa Cruz province, Argentina, a provincial natural protected area (Figure 5a). At the time of the wreck, it was carrying passengers and cargo; it sank after hitting a large rock in the middle of the estuary (Figure $5 b, c$ ). The loss of this vessel had a significant impact in the region from an economic and logistical point of view since it carried food and other supplies which had been expected for months in the remote settlements of the Patagonian coast.

\section{Results and Discussions}

The project deals with a scientific and interdisciplinary program, and through its knowledge sharing plan is expected to create an entourage of future leaders in research, management, and knowledge, with particular attention to underwater cultural sites. 
In order to provide a quantification of the successfully achieved project's six objectives, some key performance indicators (KPIs, success indicators) were defined during the planning of the project. In this sense, as expected results, and thanks to the achievement of KPIs, the project will aim to create knowledge and new tourist attractions, promoting sustainable and participatory governance of UCH in coastal areas [37]. The academic and non-academic partners along with the enterprises that make up the consortium are in this sense well embedded among the main objectives.

Thus, at the end of the project, the research results and related technologies and innovative solutions implemented should be made known to the general audience in such a way that they can be understood also by non-specialists, thereby improving the public's understanding of underwater science.

In addition, new guidelines will be available for stakeholders, such as national and local decision-makers in coastal policy, for more efficient management of and sustainable plan to preserve UCH.

The main outcome of this work is to thoroughly present the role and the impact of a new form of cultural tourism, i.e., sustainable underwater tourism, as one of the modern tourism industry's most dynamically developing branches, in today's global tourism market. Underwater cultural tourism will represent tourism in all aspects, and clearly, it will be far more than just cultural heritage. In this vein, the concept of underwater cultural tourism could take hold everywhere in coastal areas, whose seas host ancient submerged resources of different kinds, such as structures or individual objects.

The growth of new and different tourist attractions with important economic repercussions and beneficial effects will favor an increasing interest of other countries in such alternative forms of sustainable tourism. These alternative forms of tourism will be perceived as a response to the significant number of countries which still lack specific strategies for managing their $\mathrm{UCH}$. In fact, despite growing attention in tourism and culture for most of the coastal areas, not all countries have yet ratified the UNESCO Convention on the Protection of the Underwater Cultural Heritage [2].

To increase the impact of the project beyond the groups of stakeholders with a direct potential interest in project outcomes, TECTONIC will also target the following groups.

1. Businesses and policymakers: the provided information should help policymakers to understand the main concept and approach of the project and the value that it will bring to the economy and tourism.

2. Extra-EU, EU, national, regional, and local authorities: the provided information should help such authorities to understand how the TECTONIC approach could enable potential benefits at the territorial level, with repercussions on the economy and tourism, especially along coastal areas and where $\mathrm{UCH}$ is present.

3. The general public: the provided information should help the public to understand the main concepts and approach of TECTONIC and the value that it will bring to society.

The expected impact of the proposed measures will be supported from reaching the KPIs, using different channels and dissemination tools such as social media, journals, newspapers, newsletters, press releases, conferences, etc. To meet the KPIs, the following results must be achieved: (a) improve existing materials and experiment with new ones suitable for the protection of remains and for limiting the decay processes underwater (e.g., marketable coatings, adhesives, protective and consolidating materials); (b) develop more effective forecasting models capable of quantifying degradation phenomena occurring in UCH by exploiting artificial intelligence (AI) methods applied to environmental parameters data and multi-sensors images acquired periodically on underwater pilot sites; and (c) extend the use of virtual and augmented reality technologies for developing applications in which the public can enjoy the reconstructions of the underwater sites by experiencing a virtual dive in the past (especially for non-divers).

In this way, it will become essential that the rules and best practices leading the preservation, management, and restoration of ancient underwater cultural sites should be applied by each country being responsible within the framework of its own culture and traditions in a sustainable way. 


\section{Final Remarks}

In the framework of the TECTONIC project, a transversal customizable modular tool for the management of UCH will be developed, suitable to be applied in the submerged environment and addressing a wide range of appropriate solutions $[5,8,9,14,24-37]$ that are still missing or are very scarce in the market of cultural and sustainable tourism. Up to now, the research addressed the different sectors separately.

The current ethos within underwater archaeology and conservation is mainly to preserve UCH in situ, that is to say where it lies on the seabed or in other water environments and - under certain conditions-as the ultimate form for preventive conservation. Within Europe, this has been politically galvanized by the Valetta Treaty [1] and internationally by UNESCO's Convention for the Protection of the UCH [2].

Starting from these premises, the TECTONIC project intends to be state-of-the-art in different ways. In particular, the project will increase and advance the state-of-the-art UCH research, innovation, and tourism in four main areas of competence: (1) new preservation, conservation and restoration strategies; (2) innovation in tools and products; (3) an improved understanding of the concept of valorization, by implementing dissemination strategies; and (4) the planning and development of a new training program and guidelines related to $\mathrm{UCH}$.

The results of this research will contribute to creating strong outcomes available to regional/national and international political decision-makers and experts in the sector, for a future management plan and for the creation of sustainable resources, able to promote the management and conservation of underwater sites related to the conservation of waterlogged materials.

Beyond the scientific impact, the results of this research will contribute to increasing the know-how also towards the general public, local communities, and tourists, showing the potential benefits that these will bring, also on the economy and for jobs.

The dissemination activities and the use of new tools, materials, and technologies for the promotion and protection of $\mathrm{UCH}$ will encourage more sustainable management of the pilot sites, or, more generally, the coastal areas hosting $\mathrm{UCH}$, improving awareness among the countries and communities about the importance of the cultural heritage lying underwater. In this sense, the project outcomes that will be achieved will be targeted for different types of stakeholders and audiences. These include direct potential users of the project results (i.e., researchers, experts in $\mathrm{UCH}$, etc.) as well as other stakeholders, who may be directly affected (i.e., companies that produce marketable products) or have an indirect interest (managing bodies of $\mathrm{UCH}$, port authorities, ministries of cultural heritage, etc.) in the underwater cultural heritage field.

Future studies will be aimed at analyzing data and reporting the results obtained from the progress of the project, following a scientific, multidisciplinary, and methodological approach. TECTONIC's progress and outcomes will also be available to the potential and vast audience at the official project's website [38].

Particular attention will be paid to the study of the materials and environmental conditions at the pilot sites and to the new technologies developed in the framework of conservation and fruition of UCHs.

Author Contributions: Writing—original draft preparation, M.R., M.F.L.R., and D.E.; writing—review and editing, M.R., M.F.L.R., G.A., A.B., A.V., F.B., B.D.P., A.L., S.N., M.N., G.P., J.P., and D.E.; project administration, M.F.L.R., M.R., F.B., and M.R.; and funding acquisition, M.F.L.R. All authors have read and agreed to the published version of the manuscript.

Funding: This research was funded by the European Union's Horizon 2020 Research and Innovation program under the Marie Skłodowska-Curie Grant Number 873132.

Acknowledgments: This project has received funding from the European Union's Horizon 2020 Research and Innovation program under the Marie Skłodowska-Curie Grant Agreement No. 873132. The authors want to thank the project officer at the REA (Research Executive Agency), Aleksandra Schoetz-Sobczak, and all the members of the partnership that are contributing to the project.

Conflicts of Interest: The authors declare no conflict of interest. 


\section{References}

1. Treaty, T. Convention for the Protection of the Archaeological Heritage of Europe (Valletta, 1992); Council of Europe: Strasbourg CEDEX, France, 1992.

2. UNESCO. Convention on the Protection of the Underwater Cultural Heritage; UNESCO: Paris, France, 2001.

3. Davidde, B. Underwater archaeological parks: A new perspective and a challenge for conservation-the Italian panorama. Int. J. Naut. Archaeol. 2002, 31, 83-88.

4. Davidde, B. Methods and strategies for the conservation and museum display in situ of underwater cultural heritage. Archaeol. Maritima Mediterr. 2004, 1, 137-150.

5. Gregory, D.; Matthiesen, H. Conservation and management of archaeological site. Preserving Archaeological Remains in Situ. In Proceedings of the 4th International Conference, National Meuseum of Copenhagen, Copenhagen, Denmark, 8-10 April 2012; Volume 14, p. 489.

6. Bruno, F.; Gallo, A.; Barbieri, L.; Muzzupappa, M.; Ritacco, G.; Lagudi, A.; La Russa, M.F.; Ruffolo, S.A.; Crisci, G.M.; Ricca, M.; et al. The CoMAS project: New materials and tools for improving the in-situ documentation, restoration and conservation of underwater archaeological remains. Mar. Technol. Soc. J. 2016, 50, 108-118. [CrossRef]

7. Alvik, R.; Tikkanen, S.; Palma, P.; Gregory, D.; Leino, M.; Jöns, H.; Wessman, S.; Cederlund, C.O.; Oosting, R.; Kresse, W.; et al. Moss. Monitoring, safeguarding and visualizing north-european shipwreck sites: Common european cultural heritage-Challenges for cultural resource management. Natl. Board Antiq. Helsinki 2004, 1, 137-150.

8. Trakadas, A.; Firth, A.; Gregory, D.; Elkin, D.; Guerin, U.; Henderson, J.; ·Kimura, J.; Scott-Ireton, D.; Shashoua, Y.; -Underwood, C.; et al. The Ocean Decade Heritage Network: Integrating Cultural Heritage within the UN Decade of Ocean Science 2021-2030. J. Marit. Archaeol. 2019, 14, 153-165. [CrossRef]

9. Gifford, J.A.; Redknap, M.; Flemming, N.C. The UNESCO International Survey of Underwater Cultural Heritage. World Archaeol. 1985, 16, 373-376. [CrossRef]

10. Argyropoulos, V.; Stratigea, A. Sustainable Management of Underwater Cultural Heritage: The Route from Discovery to Engagement-Open Issues in the Mediterranean. Heritage 2019, 2, 98. [CrossRef]

11. La Russa, M.F.; Ruffolo, S.A.; Ricci, S.; Davidde, B.; Barca, D.; Ricca, M.; Capristo, V. A Multidisciplinary approach for the study of underwater artefacts: The case of Tritone Barbato marble statue (Grotta Azzurra, Island of Capri, Naples). Period. Mineral. 2013, 82, 101-111.

12. Aloise, P.; Ricca, M.; La Russa, M.F.; Ruffolo, S.A.; Belfiore, C.M.; Padeletti, G.; Crisci, G.M. Diagnostic analysis of stone materials from underwater excavations: The case study of the Roman archaeological site of Baia (Naples, Italy). Appl. Phys. A-Mater. 2014, 114, 655-662. [CrossRef]

13. Ricca, M.; La Russa, M.F.; Ruffolo, S.A.; Davidde, B.; Barca, D.; Crisci, G.M. Mosaic marble tesserae from the underwater archaeological site of Baia (Naples, Italy): Determination of the provenance. Eur. J. Mineral. 2014, 26, 323-331. [CrossRef]

14. Gregory, D.J.; Manders, M. Best practices for locating, surveying, assessing, monitoring and preserving underwater archaeological sites. In SASMAP Guideline Manual 2; SASMAP Project: Amersfoort, The Netherlands, 2015.

15. La Russa, M.F.; Ricca, M.; Belfiore, C.M.; Ruffolo, S.A.; Álvarez De Buergo Ballester, M.; Crisci, G.M. The Contribution of Earth Sciences to the Preservation of Underwater Archaeological Stone Materials: An Analytical Approach. JCS 2015, 6, 335-348.

16. Ricca, M.; Belfiore, C.M.; Ruffolo, S.A.; Barca, D.; Alvarez De Buergo, M.; Crisci, G.M.; La Russa, M.F. Multi-analytical approach applied to the provenance study of marbles used as covering slabs in the archaeological submerged site of Baia (Naples, Italy): The Case of the "Villa con ingresso a protiro". Appl. Surf. Sci. 2015, 357, 1369-1379. [CrossRef]

17. Ricca, M.; Comite, V.; La Russa, M.F.; Barca, D. Diagnostic analysis of bricks from the underwater archaeological site of Baia (Naples, Italy): Preliminary results. Rend. Online Soc. Geol. It. 2016, 38, 85-88. [CrossRef]

18. Cámara, B.; Álvarez de Buergo, M.; Bethencourt, M.; Fernández-Montblanc, T.; La Russa, M.F.; Ricca, M.; Fort, R. Biodeterioration of marble in an underwater environment. Sci. Total Environ. 2017, 609, 109-122. [CrossRef]

19. Papatheodorou, G.; Geraga, M.; Georgiou, N.; Christodoulou, D.; Dimas, X.; Fakiris, E.; Ferentinos, G. Marine Geo-archaeological survey in the Straits of Salamina and in Ampelakia Bay. Hellenic Maritime Museum. 2020, in press. 
20. Papatheodorou, G.; Geraga, M.; Christodoulou, D.; Iatrou, M.; Fakiris, E.; Heath, S.; Baika, K. A marine geoarchaeological survey, Cape Sounion, Greece: Preliminary results. Mediterr. Archaeol. Archaeom. 2014, 14, 357-371.

21. Davidde Petriaggi, B.; Galiatsatou, P.; Medaglia, S. The submerged "Villa of the Dolia" near ancient Epidaurus. The preliminary results of the first excavation and conservation campaign. In Annuario Della Scuola Archeologica di Atene e delle Missioni Italiane in Oriente; Scuola Archeologica Italiana di Atene: Atene, Italy, 2019; Volume 97.

22. Medaglia, S. Ricerche Storiche in Calabria: Modelli e prospettive (edited by Lena G.) In Per un Censimento Dei Relitti aNtichi Lungo la Costa Crotonese; Nota Preliminare: Cosenza, Italy, 2008.

23. Medaglia, S. Carta Archeologica della provincia di Crotone, paesaggi storici e insediamenti nella Calabria centro-orientale dalla Preistoria all'Altomedioevo. In Ricerche, Collana del Dipartimento di Archeologia e Storia delle Arti, IV; Università della Calabria: Rende, Italy, 2010.

24. Bruno, F.; Barbieri, L.; Mangeruga, M.; Cozza, M.; Lagudi, A.; Čejka, J.; Liarokapis, F.; Skarlatos, D. Underwater augmented reality for improving the diving experience in submerged archaeological sites. Ocean Eng. 2019, 190, 106487. [CrossRef]

25. Ruffolo, S.A.; Ricca, M.; Macchia, A.; La Russa, M.F. Antifouling coatings for underwater archaeological stone materials. Progr. Orga. Coat. 2017, 104, 64-71. [CrossRef]

26. Randazzo, L.; Ricca, M.; Ruffolo, S.; Aquino, M.; Davidde Petriaggi, B.; Enei, F.; La Russa, M.F. An Integrated Analytical Approach to Define the Compositional and Textural Features of Mortars Used in the Underwater Archaeological Site of Castrum Novum (Santa Marinella, Rome, Italy). Minerals 2019, 9, 268. [CrossRef]

27. Randazzo, L.; Ricca, M.; Pellegrino, D.; La Russa, D.; Marrone, A.; Macchia, A.; Rivaroli, L.; Enei, F.; La Russa, M.F. Anti-fouling additives for the consolidation of archaeological mortars in underwater environment: Efficacy tests performed on the apsidal fishpond of Castrum Novum (Rome, Italy). IJCS 2020, 11, $243-250$.

28. Bruno, F.; Lagudi, A.; Muzzupappa, M.; Lupia, M.; Cario, G.; Barbieri, L.; Saggiomo, R. Project VISAS: Virtual and augmented exploitation of submerged archaeological sites-overview and first results. Mar. Technol. Soc. J. 2016, 50, 119-129. [CrossRef]

29. Bruno, F.; Barbieri, L.; Lagudi, A.; Cozza, M.; Cozza, A.; Peluso, R.; Muzzupappa, M. Virtual dives into the underwater archaeological treasures of South Italy. Virtual Real. 2018, 22, 91-102. [CrossRef]

30. Bruno, F.; Barbieri, L.; Lagudi, A.; Mangeruga, M.; Pupo, F.; Casavola, A. Cooperative Monitoring System for Diver Global Localization and Operation Support. In International Conference on Design, Simulation, Manufacturing: The Innovation Exchange; Springer: Cham, Switzerland, 2020; pp. 410-421.

31. Vasilijević, A.; Nad, D.; Mandi, F.; Miškovi, N.; Vukić, Z. Coordinated navigation of surface and underwater marine robotic vehicles for ocean sampling and environmental monitoring. IEEE-ASME Trans. Mech. 2017, 22, 1174-1184. [CrossRef]

32. Tonacci, A.; Lacava, G.; Lippa, M.A.; Lupi, L.; Cocco, M.; Domenici, C. Electronic nose and AUV: A novel perspective in marine pollution monitoring. Mar. Technol. Soc. J. 2015, 49, 18-24. [CrossRef]

33. Scaradozzi, D.; Zingaretti, S.; Ciuccoli, N.; Costa, D.; Palmieri, G.; Bruno, F.; Ritacco, G.; Cozza, M.; Raxis, P.; Tzifopanopoulos, A. Lab4Dive Mobile Smart Lab for Augmented Archaeological Dives. In IOP Conference Series: Materials Science and Engineering; IOP Publishing: Bristol, UK, 2018; Volume 364.

34. Papachristopoulou, I.; Filippides, A.; Fakiris, E.; Papatheodorou, G. Vessel-based photographic assessment of beach litter in remote coasts. A wide scale application in Saronikos Gulf, Greece. Mar. Pollut. Bull. 2020, 150. [CrossRef]

35. Ferentinos, G.; Fakiris, E.; Christodoulou, D.; Geraga, M.; Dimas, X.; Georgiou, N.; Kordella, S.; Papatheodorou, G.; Prevenios, M.; Sotiropoulos, M. Optimal sidescan sonar and subbottom profiler surveying of ancient wrecks: The 'Fiskardo' wreck, Kefallinia Island, Ionian Sea. J. Archaeol. Sci. 2020, 113, 105032. [CrossRef]

36. Chamoso, P.; Bartolomé, Á.; García-Retuerta, D.; Prieto, J.; De La Prieta, F. Profile generation system using artificial intelligence for information recovery and analysis. J. Ambient. Intell. Humaniz. Comput. 2020, in press. [CrossRef] 
37. Rempis, N.; Alexandrakis, G.; Tsilimigkas, G.; Kampanis, N. Coastal use synergies and conflicts evaluation in the framework of spatial, development and sectoral policies. Ocean Coast. Manag. 2018, 166, 40-51. [CrossRef]

38. TECTONIC Project Website. Available online: https://www.tectonicproject.eu/ (accessed on 1 February 2020).

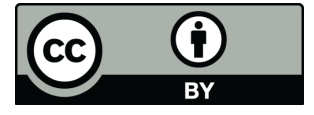

(C) 2020 by the authors. Licensee MDPI, Basel, Switzerland. This article is an open access article distributed under the terms and conditions of the Creative Commons Attribution (CC BY) license (http://creativecommons.org/licenses/by/4.0/). 